\title{
UNIVERSIDADE FEDERAL DO PARANÁ
}

SETOR DE CIÊNCIAS DA SAÚDE

\author{
DEPARTAMETO DE ENFERMAGEM
}

CURSO DE GRADUAÇÃO EM ENFERMAGEM

\section{O CORPO OBESO E A PERCEPÇÃO DE SI}

\author{
CAROLINA ZOTTIS \\ LILIANA MARIA LABRONICI
}

End. Rua Amintas de Barros, 540, apto. 144

Telefone para contato: 9958-1427 ou 3630962

Data de Envio: 26 de março de 2003.

\section{CURITIBA}

2003 


\title{
O CORPO OBESO E A PERCEPÇÃO DE SI*
}

\author{
[The Obese Body and Self Perception]
}

\section{Resumo}

Trata-se de uma pesquisa de iluminação fenomenológica fundamentada no pensamento de Maurice Merleau-Ponty, que tem como objetivo compreender a percepção do corpo obeso sobre si. Foram realizadas 10 entrevistas gravadas no período de 20 de janeiro a 20 de fevereiro de 2003, com clientes obesos em acompanhamento no ambulatório de nutrição de um hospital escola de grande porte da cidade de Curitiba. A análise dos discursos se deu mediante três momentos: a descrição, a redução e a compreensão fenomenológica, o que permitiu a identificação de uma unidade temática que foi subjetivamente categorizada em: "a alteração da imagem corporal aflorando sentimentos de tristeza e o isolamento". Constatou-se que os mecanismos de defesa do ego, negação do corpo e o isolamento são comportamentos freqüentes e associados à baixa auto estima nos corpos obesos. Estes mecanismos, relativamente inconscientes, envolvem um grau de autodecepção e distorção da realidade podendo constituir em respostas mal adaptadas ao estresse; a alteração da imagem corporal associada à baixa auto-estima nos corpos obesos são comportamentos que têm como significado a insatisfação consigo mesmo. Evidenciou-se que a sociedade ao impor padrões estéticos de "beleza magra", ao mesmo tempo em que exclui o corpo obeso do seu meio, suscita sentimentos de desprezo e menos valia em relação a ele próprio.

Palavras-chave: Enfermagem; Imagem corporal; Obesidade 


\title{
O CORPO OBESO E A PERCEPÇÃO DE SI*
}

\author{
[The Obese Body and Self Perception]
}

\author{
Carolina Zottis** \\ Liliana Maria Labronici***
}

\section{INTRODUÇÃO}

A obesidade é, segundo evidências históricas, provavelmente a enfermidade metabólica mais antiga que se conhece. Ela aparece na história há mais de vinte mil anos em obras nas quais mulheres obesas eram pintadas e esculpidas (REPETTO, 1998).

Desde o período greco-romano as complicações que a obesidade traz à saúde humana são descritas e podem ser observadas nos textos de Hipócrates, nos quais há descrições de que a morte súbita era muito mais freqüente em obesos. Embora a obesidade fizesse parte do contexto daquela época, ela, como até hoje, tinha uma conotação de desprezo. Ela era vista no mundo como uma doença social e moral, não sendo uma condição que dependesse de tratamento, mas de disciplina, força de vontade e auto estima, visto que sua origem era atribuída a maus hábitos alimentares, inatividade física e até mesmo ao descuido.

Nos últimos anos, a comunidade científica vem assistindo a um aumento importante no número de informações sobre a obesidade. A evolução dos conhecimentos fez com que com que a obesidade passasse a ser considerada uma doença crônica, progressiva e letal.

\footnotetext{
* Este trabalho é um recorte da monografia intitulada "O Corpo Obeso e a Percepção de Si” defendida em 12 de março de 2003.

** Enfermeira graduada em Enfermagem pela UFPR.

*** Professora Adjunta do Departamento de Enfermagem da UFPR. Doutora em Enfermagem pela UFSC. Membro do Grupo de Estudos Multiprofissional em Saúde do Adulto - GEMSA.
}

De acordo com os dados da Associação Brasileira para o Estudo da Obesidade (ABESO) em 2002, 13\% das mulheres e $8 \%$ dos homens brasileiros sofrem de obesidade, ao mesmo tempo, $40 \%$ da população sofre de excesso de peso. Segundo DAMIANI (2000), estatísticas apresentadas pela "National Health and Nutrition Examination Surveys" (NHANES) em 1998, 50\% da população de americanos apresenta sobrepeso ou obesidade. 
Diante destes cenários, recentemente a Organização Mundial de Saúde (OMS) considerou a obesidade como uma epidemia global, que vêm afetando não só os países industrializados como também de forma crescente, aqueles em desenvolvimento sobrepondo-se ao problema da fome e desnutrição. Permeando essa problemática que o obeso se depara, existem ainda os enfrentamentos impostos pela sociedade, preconceitos e restrições, imposição de um padrão de beleza, dificuldades no dia-a-dia em relacionamentos, transporte, locomoção, vestuário e no trabalho.

Segundo ZOTTIS (2002), os corpos obesos encontram dificuldades até mesmo nas tarefas mais simples da vida cotidiana, como por exemplo, na própria higiene corporal e nos afazeres domésticos. Realizá-los torna-se um desafio e perder peso significa recuperar a qualidade de vida e a auto-estima, ou seja, retomar as atividades do cotidiano e reintegrarse ao seu papel social.

Devido à supervalorização da estética e conseqüente rejeição social sofrida pelo obeso, com freqüência, desenvolvem depressão emocional entre outros distúrbios de comportamento e auto-imagem, motivo pelo qual é imprescindível compreender a percepção que o corpo obeso tem sobre sua própria imagem.

Diante do exposto este estudo tem como questão norteadora:

- Qual é o significado da obesidade para o corpo obeso?

Objetivo geral:

- Compreender a percepção que o corpo obeso tem de si próprio.

\section{REFERENCIAL TEÓRICO E METODOLÓGICO}

Ao buscar a compreensão sobre a percepção que o corpo obeso tem de si próprio fez-se necessário fundamentar esta pesquisa, que se caracteriza como sendo qualitativa e de abordagem fenomenológico hermenêutica, no pensamento de Maurice Merleau-Ponty, conhecido como filósofo da existência, do corpo e fenomenólogo da percepção.

Maurice Merleau-Ponty "compreende o homem como sendo corpo, consciência encarnada, como essência expressa pelo corpo visto-vidente, sensível e, por isso, "sentisentant", é também tocado-tocante, isto é, como corporeidade, visto em processo de coexistência, num recruzamento, processo este que permite, pela experiência vivenciada, apreendermos a trama, a teia complexa de relações que institui a realidade humana, 
fundamentada na palavra, no significado que cada corpo vivente atribui" (LABRONICI, 2002, p.34).

O corpo na concepção do filósofo Maurice Merleau-Ponty (1994) é produtor e portador de significado, é fonte natural de sentido; é espaço expressivo, é o nosso meio geral de ter o mundo, porquanto ele me abre ao mundo e nele me coloca em situação e em comunicação com a espaciotemporalidade ${ }^{2}$, com o mundo visto não mais como a soma de objetos determinados, mas como horizonte de possibilidades infinitas, motivo pelo qual não posso possuí-lo, e como horizonte dissimulado de nossa experiência sem cessar, como meio e campo de todos os meus pensamentos e de todas as minhas percepções explícitas. Ele é tempo e espaço, é sensibilidade, é expressão, fala, linguagem, isto é, espaço expressivo, conjunto de significações que, ao serem vividas durante nossa deambulação existencial, passam a fazer parte do nosso ser, da nossa bagagem cultural e histórica e que, fazem do corpo "memória", memória que guarda, retrata, conta e faz histórias, porque vivencia e experiencia o ser e o estar no mundo, o ser-ao-mundo em um processo de coexistência" (LABRONICI, 2002, p.34). O corpo é o espelho do nosso ser, é o nosso ancoradouro, é o veículo do ser no mundo, porquanto permite nossa deambulação existencial, nos entrelaça com o mundo e com outras corporeidades por meio da relação intencional e dialética que se dá no espaço topológico ${ }^{3}$.

A Fenomenologia consiste num método de investigação que enfatiza a complexidade da existência humana e a necessidade de se estudar a experiência vivida tal como ela se apresenta à nossa percepção (BICUDO, 2000). O termo fenomenologia significa o estudo do fenômeno, ou seja, aquilo que aparece à consciência, que é dado a partir do vivido e da realidade das vivências intencionais. O fenômeno, realidade típica do mundo humano e existencialização do sentido, mostra-se no discurso ou na descrição, é algo concreto e não idealisticamente deduzido, que passa a ser parte estrutural da consciência, e vai sendo reconhecido, à medida que sua análise se desenvolve, se

\footnotetext{
${ }^{2}$ Espaciotemporalidade: vem de espaciotemporal - visa concentrar a idéia de "na circunstância de tempo e espaço, o lugar". Em latim a palavra "espacio", que já é castelhano; o fonema "E" se antepõe por necessidade da língua, é metaplasmo de adição protética (nota do Professor Virgílio J. Balestro).

${ }^{3}$ Espaço topológico é o meio onde se circunscrevem relações de vizinhança, de envolvimento (Merleau-Ponty, 1992, p.196).
} 
aprofunda, motivo pelo qual não podemos pensar em interpretação final (LABRONICI, 2002). A fenomenologia através da descrição, que assume a forma de um texto exposto mediante a linguagem, permite analisar e interpretar hermeneuticamente a coisa percebida, isto é, o fenômeno (BICUDO, 2000). A arte da interpretação das estruturas de significados contidos na descrição chama-se hermenêutica. Esta é a busca do sentido pela interpretação (DEMO, 1995). Neste sentido, a linguagem é de fundamental importância.

\section{O PROCESSO DE OBTENÇÃO, REGISTRO E ANÁLISE DOS}

\section{DISCURSOS}

A obtenção dos discursos se deu mediante a realização de 10 entrevistas semiestruturadas gravadas com clientes que freqüentavam o ambulatório de nutrição de uma instituição hospitalar pública na cidade de Curitiba e que são encaminhados para orientação nutricional pelo serviço ambulatorial de endocrinologia por serem portadores de diferentes graus de obesidade e estarem em tratamento clínico ou acompanhamento pré e pósoperatório de gastroplastia. As entrevistas foram obtidas no período de 20 de janeiro a 20 de fevereiro de 2003. A faixa etária dos atores participantes desta amostra estavam entre 24 a 61 anos. Deste total, 09 eram do sexo feminino e 01 do sexo masculino. O peso variou entre $81,5 \mathrm{Kg}$ a $142 \mathrm{Kg}$.

No que diz respeito aos aspectos éticos, encaminhei o projeto de pesquisa ao Comitê de Ética do hospital para análise e aprovação. Antes de iniciá-la, apresentei-me para a equipe que atua no ambulatório, expliquei sobre o projeto a ser desenvolvido durante o segundo semestre letivo de 2002 e disponibilizei uma cópia.

Antes de dar início ao atendimento no ambulatório, perguntei a cada cliente se havia interesse em participar voluntariamente da pesquisa, que foi cuidadosamente explicada e que caso desejassem, seria necessário assinar o termo de consentimento livre e esclarecido. Salientei que não haveria nenhum prejuízo na assistência prestada, caso não desejassem participar, e que seria necessária a utilização do gravador durante as entrevistas para que não perdêssemos nenhum dado relevante.

Quanto a confidencialidade, assegurei aos entrevistados o sigilo de suas identidades, mediante a utilização de algarismos romanos para identificar cada uma das entrevistas. Ressalto que durante as entrevistas procurei manter uma postura de neutralidade, respeito e 
abertura, atenta às expressões corporais, uma vez que o corpo é expressão, fala e linguagem.

A entrevista teve como provocação inicial a seguinte solicitação:

- Fale-me sobre o início de sua obesidade até o momento atual.

A outra solicitação foi:

- Fale-me como você se sente sendo um corpo obeso.

As entrevistas foram transcritas na íntegra possibilitando a sua compreensão.

A análise dos discursos ocorreu mediante a trajetória fenomenológica descrita por MARTINS (1992), que consiste em três momentos: a descrição, a redução e a compreensão fenomenológica.

A descrição é o primeiro momento da trajetória da pesquisa qualitativa, não admite julgamentos e avaliações, é de fundamental importância como afirma MARTINS (1992) nos estudos fenomenológicos visto que se desenvolvem sem hipóteses explícitas, porque têm como objetivo oferecer uma oportunidade de revelação da experiência humana, do vivenciado sem restrições previamente estabelecidas (BICUDO, 2000). Segundo a autora, a descrição se expõe mediante a linguagem, permite analisar e interpretar hermeneuticamente a coisa percebida, os acontecimentos tais como se mostram, ou seja, como se apresentam à consciência, a partir da realidade vivencial, isto é, das vivências intencionais da consciência.

Para extrairmos das descrições os significados e os caracteres fundamentais contidos nos discursos, é necessário fazer uso da redução. A redução tem como objetivo principal "chegar à essência, à natureza própria daquilo que interrogamos". Podemos chegar à redução fenomenológica por meio da reflexão. É a partir da redução que obteremos a compreensão fenomenológica, extraindo as unidades de significado apontadas pela experiência/consciência do sujeito.

Para realizar a redução foi preciso uma leitura atenciosa de cada um dos discursos com o objetivo de me interar com o conteúdo na sua totalidade, ou seja, me familiarizar com a realidade vivenciada pelo sujeito tal como ele a descreveu, sem nenhuma tentativa de interpretá-la. Em seguida li novamente cada um dos discursos procurando identificar as convergências e as divergências entre as falas do sujeito. Então, removi do discurso os fragmentos, as partes significativas em que os sujeitos, através de sua imagem, expressam 
sua vivencia mediante uma pluralidade de formas. Desta forma, obtive as seguintes unidades de significado:

“... as rugas começam a aparecer demais, pelanca ca...(I)

“...Ah, nem me olho...eu não consigo mais me ver...só minha barriga! Só consigo ver minha barriga!...nem o médico que foi fazer meu exame não conseguiu ver nadinha aqui...Eu só enxergo meus pés, minhas pernas e minha barriga... a barriga esconde tudo, então gordo não se olha no espelho não...passa assim na frente do espelho, olha pra outro lado, nem pra pentear o cabelo mais...”

“...Ai, pesado, horrível...(VII)

“...Horrível né...(IX)

“...Eu chego assim na frente do espelho, fico olhando, não me reconheço de imediato...eu sou um barril, sou redonda de todos os lados...(X)

Após análise e reflexão transformei as unidades de significados dos sujeitos em expressão minha como pesquisadora: "A negação do corpo". Da síntese das unidades de significado que convergiram na redução emergiu o tema: "A alteração da imagem corporal aflorando sentimentos de tristeza e o isolamento".

O terceiro momento da trajetória é a compreensão fenomenológica que permite “a captação das vivências sem uso de explicações e da experiência vivida subjetivamente. É o momento e a tentativa de desvelar, de especificar possíveis "significados" na descrição" (LABRONICI, 2002, p.52). Para obter a interpretação das narrativas contidas nas estruturas de significados utilizou-se a hermenêutica. Há que se ressaltar que na fenomenologia o fenômeno, que é entendido como realidade típica do mundo humano e existencialização do sentido, mostra-se no discurso. Entretanto, para que possamos desvelar um fenômeno faz-se necessário compreendê-lo.

\section{A COMPREENSÃO DO FENÔMENO}

A construção do conhecimento fundamentada na Fenomenologia se dá não apenas pela descrição do vivido, visto que esta não nos permite a compreensão do fenômeno.

Compreender para MERLEAU-PONTY (1992, p.180), “é aprender pela coexistência, literalmente, em estilo e assim atingir de um golpe os pontos longínquos desse estilo e desse aparelho cultural". Isto é, compreender é alcançar algo com a inteligência, é a 
faculdade de perceber e aprender, ou seja, é ter experiência ou o conhecimento de algo ao alcançar sua significação. Neste sentido a compreensão é um modo de conhecimento interpretativo, no qual o pesquisador trabalha com a sua subjetividade.

Ao introduzir a subjetividade sobre os discursos dos corpos obesos na análise, identifiquei o tema "A alteração da auto-imagem aflorando sentimentos de tristeza e o isolamento". Para que fosse possível compreendê-lo, busquei na literatura os conceitos de imagem corporal e auto-estima e procurei também relacioná-los as demonstrações de comportamentos de negação e isolamento relatados pelos corpos obesos visto que a obesidade, além de ser um problema de saúde pública, é um fator indutor de comportamentos individuais e sociais. A obesidade, na sociedade contemporânea, não é apenas uma doença que aflige o homem, mas também o exclui do "imaginário popular de uma estética socializada" (SICHIERI, 1998, p.15).

É importante lembrar que a obesidade, muito distante de ser uma "fraqueza de caráter, é uma doença que afeta o homem nos seus aspectos físico, psíquico e social" (FRANQUES, 2002, p.75). ou seja, afeta o corpo na sua totalidade. A prevalência crescente da obesidade reforça, nos dias de hoje, uma popularização banalizada da própria obesidade (SICHIERI, 1998). Para a autora, há um mercado de alimentos, equipamentos e vestuário dirigido ao obeso e aos que têm medo de se tornarem obesos, esta indústria, tenta impor e reordenar hábitos, desconsiderando a causalidade da obesidade.

De modo geral, o corpo obeso experimenta diversos tipos de tratamento para a redução de peso, e tudo que for prometido a ele, em se tratando de emagrecimento, é aceito sem o menor cuidado com os possíveis efeitos adversos, principalmente se o tratamento proposto for uma fórmula mágica que não implique em grandes esforços para a pessoa. Contudo, apesar do empenho nas terapias contra a obesidade, quanto à perda de peso e sua manutenção, os dados da literatura não são nada animadores (FRANQUES, 2002). Para o autor, apenas $20 \%$ dos indivíduos que reduzem seu peso corporal conseguem mantê-lo por mais de um ano, entretanto, após cinco anos, somente 5\% dos clientes conseguem manter seu peso dentro dos limites normais. Assim, a grande maioria volta ao seu peso inicial e, por vezes, o ultrapassa. Estes dados fazem-nos refletir sobre o quanto os seres obesos experienciam sentimentos de fracasso, tristeza, culpa e insatisfação consigo mesmos. 
Sabe-se que os efeitos adversos da obesidade não são apenas aqueles relacionados às doenças clínicas. Há uma desvantagem social evidente para o corpo obeso. Mesmo uma condição leve de sobrepeso confronta-se com o ideal de magreza e beleza culturalmente estabelecidos pela sociedade, conduzindo, de tal forma, que essas pessoas se envergonhem de sua condição e sintam o preconceito e a discriminação (SALLET et al., 2001).

A nossa sociedade supervaloriza a magreza, o corpo belo produzido nas academias, ou ainda produzido pela modelagem terapêutica mediante implantes de silicone, cirurgias plásticas, entre outros, revelando o culto ao corpo belo (LABRONICI, 2002, p.102) e, ao mesmo tempo, produz julgamentos sociais negativos em relação ao corpo obeso. Adjetivos pouco honrosos como: "feio, relaxado, preguiçoso e incompetente”, são direcionados ao ser obeso desde a infância, sugerindo a idéia de que o indivíduo obeso é o responsável por sua obesidade devido a falta de vontade e de autocontrole. O drama psicológico vivenciado pelo corpo obeso, devido ao forte preconceito social pode ser evidenciado nas seguintes falas:

“...a pessoa obesa, ela é...caçoam dela. Todo mundo fala assim: gordinha, pancinha...e tem pessoas que chamam você, você ta pesada hein! (V)

“tem os outros que falam que a gente é gordo porque é relaxado...porque não fecha a boca...porque não tem força de vontade...Porque o gordo é ponto de referência, se eu to parada, você ta do meu lado, o povo vai dizer: aquela que ta do lado da gorda...porque você é gordo, você não é gente...

O preconceito social sofrido pelo corpo obeso propicia que mensagens e atributos negativos sejam internalizados e passem a constituir fatores desencadeadores de problemas psicológicos observados nessa população (SALLET et al., 2001). O sofrimento moral vivenciado pelo corpo obeso devido à discriminação em sua vida profissional e acadêmica, relaciona-se diretamente ao grau de obesidade, ou seja, quanto maior o Índice de Massa Corporal (IMC), mais problemas psicológicos surgem. Desta forma, além de carregar o peso de seu corpo, o corpo obeso leva consigo o peso da culpa e da responsabilidade por sua obesidade, dando início ao que FRANQUES (2002) denominou "Círculo Vicioso do Comportamento do Obeso", conforme o esquema representativo a seguir:

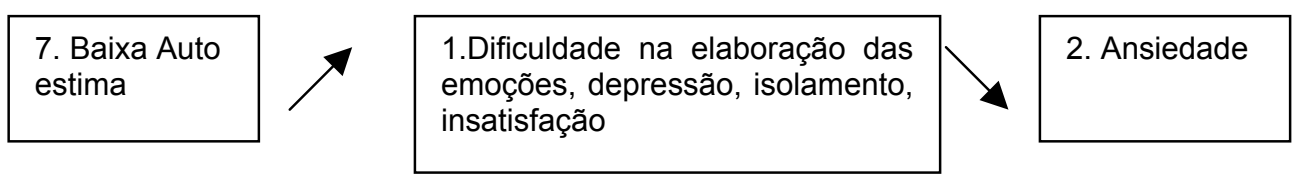




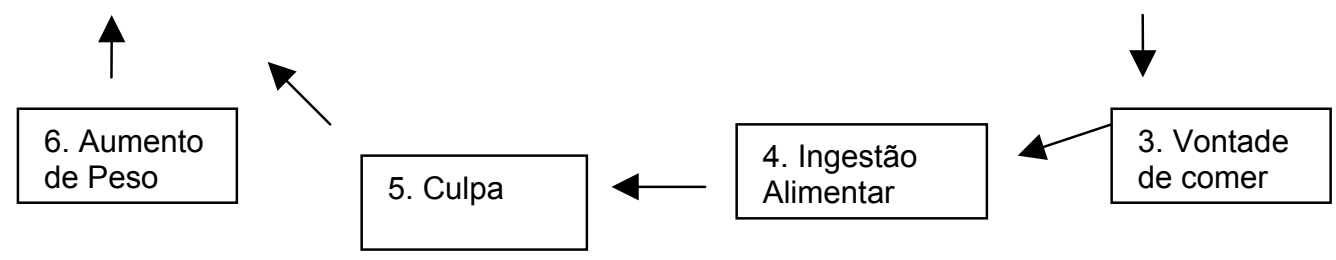

Sabe-se que todo conhecimento, inclusive o de si mesmo passa pelo corpo. É o corpo que está envolvido no processo de compreender, recordar e sociabilizar-se com os outros corpos. Para MERLEAU-PONTY (1994), é a partir do corpo que se pode estar no mundo em relação com os outros e com as coisas, o corpo e o mundo estão entrelaçados e são constituídos pelo mesmo tecido. Pensando o corpo como resultado de todas as nossas experiências conscientes e até mesmo inconscientes, muitas vezes o vemos como algo misterioso.

Para GONÇALVES (2000, p.106), “a imagem corporal é ao mesmo tempo, constante e mutável. A imagem do corpo é, pois, uma reconstrução constante do que o indivíduo percebe de si e das determinações inconscientes que ele traz de seu diálogo com o mundo". Ela é "a figuração do nosso corpo formada em nossa mente, ou seja, o modo pelo qual o corpo se apresenta para nós" (SCHILDER, citado por CORDÁS, 2002, p.78). Para o autor, a percepção da imagem corporal dá-se pelo grande número de experiências que o indivíduo acumula durante a vida, isto é, ela é "o retrato mental que a pessoa faz da sua própria aparência física e das atitudes e sentimentos em relação a ela”. SHAW e D’ANGOUR (2001, p.22) afirmam que “um homem nada mais é do que o produto de seus pensamentos, ele torna-se aquilo que pensa".

A imagem corporal que o obeso tem de si é distorcida, e essa distorção é tanto maior quanto mais antiga for a sua obesidade (FRANQUES, 2002). É importante salientar que o corpo obeso perde a noção de sua imagem corporal durante o tempo em que aumenta e diminui de peso várias vezes, durante tentativas de emagrecimento fracassadas (SCHILDER, 1980).

SHAW e D'ANGOUR (2000, p.63), nos fazem uma importante reflexão afirmando que "qualquer um que se mire no espelho da água verá, antes de mais nada, o seu próprio rosto. Todos os que buscam a si mesmos arriscam-se a uma confrontação consigo mesmos. 
O espelho adula; ele mostra fielmente tudo sobre o que está encarando, esta confrontação é o primeiro teste de coragem em nosso interior, um teste suficiente para assustar e afastar a maioria das pessoas".

Como um mecanismo de defesa, o corpo obeso deixa de se olhar no espelho, deixa de pesar-se, foge da balança e não tira fotos. A negação da própria imagem corporal é definida por STUART e LARAIA (2002, p.143), como uma "fuga das realidades desagradáveis ignorando-as ou recusando-as a reconhecê-las".

Para TAYLOR (1992), a imagem corporal é a imagem mental do próprio corpo, que pode ser realista ou parte da fantasia que busca satisfazer um desejo do indivíduo sobre si mesmo. Nos dias de hoje, podemos observar que as alterações da imagem corporal estão presentes em várias patologias, dentre as quais a obesidade (APPOLINÁRIO, 1998). Ameaças à imagem corporal e, destas à auto-estima, muitas vezes são acompanhadas de sentimentos de vergonha, inadequação e culpa (BRUNNER; SUDDARTH, 1999).

Estudiosos da área têm uma tendência em considerar as alterações da imagem corporal como uma perturbação psicológica comum da obesidade. Um conceito mais abrangente de alteração da imagem corporal seria considerar o próprio corpo como alterado ou deformado, grotesco e até mesmo repugnante, supondo que os outros tendem a tratá-lo com desprezo e hostilidade (APPOLINÁRIO, 1998).

A idéia de que o corpo obeso é um indivíduo perturbado e com uma personalidade característica é um dos vários mitos relacionados à obesidade. Ao pesquisar sobre esta temática na literatura, podemos encontrar múltiplas tentativas de definir um perfil psicopatológico nos obesos. Contudo, os estudos mostram que os obesos têm um grau de morbidade psiquiátrica próximo da população em geral, não evidenciando um tipo de personalidade específica do obeso. Entretanto, algumas peculiaridades psicológicas são consideradas nos pacientes obesos, como os aspectos culturais relacionados à discriminação, os transtornos da imagem corporal, a baixa auto-estima e as alterações do comportamento alimentar.

Diante tanta discriminação e preconceito, fica difícil manter uma imagem corporal e uma auto-estima positiva sem a presença da depressão e outras perturbações. Os sintomas depressivos e ansiosos são freqüentemente identificados em corpos obesos, e encontram-se principalmente nas várias formas comportamentais de baixa auto-estima. 
A auto-estima é "o julgamento do indivíduo sobre seu valor pessoal, obtido pela análise de como seu comportamento se adapta ao ideal pessoal" (STUART; LARAIA, 2002, p.169). Ressalte-se que muitos corpos obesos iniciam um tratamento para perda de peso em busca de melhoras no humor, da auto-estima e dos relacionamentos interpessoais (WADDEN; STUNKARD, 1993).

Sentindo necessidade de mudança, que geralmente é acompanhada de sentimentos de insatisfação e ansiedade, o homem lança mão de mecanismos de adequação na tentativa de mitigá-los. No caso de pessoas obesas podemos encontrar mais freqüentemente mecanismos de defesa do ego que envolvem um grau de autodecepção e distorção da realidade (STUART; LARAIA, 2002).

Sabe-se que todos os seres humanos possuem necessidades emocionais que incluem a necessidade de amor, confiança, autonomia, identidade, auto-estima, reconhecimento e segurança, ou como denominou SCHULTZ, citado por BRUNNER e SUDDARTH (1999), de necessidades interpessoais de inclusão, controle e de afeição. Quando estas não são preenchidas desencadeiam no ser humano sentimentos e comportamentos não desejados como ansiedade, raiva e dúvida de si.

O comportamento de inclusão reflete associações entre os indivíduos e é expressado com palavras como: "interagir, comunicar e associar". A falta de inclusão é expressa por palavras como: "excluído, distante e isolado". O isolamento para KAPLAN; SADOCK; GEBB (1997), é um mecanismo de defesa que protege a pessoa dos afetos e impulsos geradores de ansiedade, e é também definido como um comportamento associado à autoestima baixa. Ele enquanto mecanismo de defesa do ego pode ser percebido nas seguintes falas:

“...ir pra praia você fica meio constrangido...a gente fica meio tímido, fica complicado estabelecer contato com outras pessoas, né, sair, a gente fica sem jeito...daí fica mais em casa, e sair tem que ser o mais rápido possivel...e a cada dia vai ficando mais desleixado com você mesmo..." (IV)

“...dai comecei a me desligar de mim,...me isolei do mundo, comecei a ficar mais em casa...(VII)

“...dai eu adotei uma postura assim, de isolamento...(X) 
O sofrimento moral produzido no corpo obeso devido à baixa auto-estima, é um sentimento de menos-valia, acompanhado de autodepreciação, e auto-acusação, ou seja, culpa, fraqueza, rejeição, inferioridade e fragilidade. Estes tipos de sentimentos são fenômenos marcantes na trajetória da depressão. Para TAYLOR (1992), a depressão é uma perturbação profunda no humor que compartilha algumas características com a tristeza. Esta é uma reação normal, comum e necessária à perda de alguma pessoa ou objeto de grande valor, já a depressão é uma elaboração patológica deste luto de duração prolongada, grave e progressivamente incapacitante. Os indícios destes sentimentos de tristeza foram encontrados nas seguintes falas:

“...eu fico triste quando eu vou por uma roupa que eu gosto, assim e não fica bem, ai Deus me livre, tenho vontade de chorar..."

“...é isso a gente fica assim, entristecido com isso, né, porque você ta fazendo tudo pra emagrecer e as pessoas não vêem..." (V)

“...você não se sente uma pessoa feliz, né, não é igual as outras...ser gordo é triste...muito triste...” (IX)

A depressão é um sintoma que faz parte de inúmeros distúrbios emocionais sem ser exclusivo de nenhum deles. A sintomatologia depressiva é variada e diferente entre as pessoas, contudo, a psicopatologia recomenda como válida a existência de três sintomas depressivos básicos, de acordo com o autor seriam: o sofrimento moral (baixa auto-estima), a inibição global (apatia e desinteresse), e o estreitamento vivencial (perda de prazer). Em suas formas, leves a depressão se revela por um profundo sentimento de mal-estar, de abatimento, de tristeza, de inutilidade e incapacidade para realizar qualquer atividade (BALLONE, 2002). Os indícios destes sentimentos foram amplamente detectados nas falas dos corpos obesos. Contudo, não se pode levar em conta a depressão como um fator isolado, há fatores ambientais de risco para sua ocorrência que, para o autor devem ser considerados. Existe uma forte relação entre a depressão e a obesidade.

As queixas físicas também estão classificadas como comportamentos associados à auto-estima baixa e a depressão. Sabe-se que a obesidade é vista como um fator de risco para várias doenças. Muitas destas queixas que foram evidenciadas nos discursos são, também, manifestações de conseqüências da obesidade, mesmo que o indivíduo tenha ou não consciência disso. Isto pode ser constatado nas falas: 
"é a coluna dói, o joelho dói..."(I)

“...sei lá cansa mais fácil, né...e não sei se por causa da obesidade também tenho artrose nos joelhos, dai tem dificuldade, não consigo ajoelhar, não consigo me agachar..."(III)

“...de uns tempo pra cá ta sendo a maior dificuldade pra mim andar, se continuar assim logo vou me entregar...dor nas juntas, dor nos pés, dor na coluna, pressão alta...e ansiedade bastante eu tenho..."(VII)

A partir da análise dos discursos, podemos evidenciar em especial as queixas físicas referentes ao sistema músculo-esquelético, através da expressão de dor e sentimentos de incapacidade devido à obesidade. Pode-se afirmar que é realmente difícil encontrar uma alteração física do organismo, como a obesidade, que não afete o corpo em sua totalidade, pois o estado de ânimo e o organismo estão indissoluvelmente atrelados.

\section{CONSIDERAÇÕES FINAIS}

O corpo obeso sofre com o preconceito e a discriminação impostos pela sociedade e pelos padrões culturais de beleza que idolatram o corpo magro como sendo belo. Isto pode ser observado diariamente através dos meios de comunicação que cultuam os corpos esguios, e ao mesmo tempo, excluem os corpos obesos de qualquer padrão estético, comportamental e profissional ideal.

A auto-imposição do padrão estético da "beleza magra" e a conseqüente insatisfação com a própria imagem corporal identificadas nas falas dos corpos obesos evidencia sentimentos de tristeza e baixa auto-estima, que são comportamentos predominantes e patológicos da depressão. Este olhar de censura social provocado pelo padrão midiático de beleza foi introjetado pelo corpo obeso (MINAYO citado por TONIAL, 2001), e as conseqüências desta introjeção reflete na maneira como ele se sente a respeito de si mesmo e na sua corporeidade no processo de coexistência com outros corpos.

Segundo TONIAL (2001, p.165), “o corpo obeso atrapalha tanto no enfrentamento do mercado de trabalho como na possibilidade de ascensão social"; ele se percebe isolado pela sociedade e excluído das atividades humanas como vida profissional e acadêmica, atividades de lazer e relacionamentos interpessoais, ao mesmo tempo, identifica-se como alvo de todas as críticas pejorativas e julgamentos sobre sua conduta. Isto pode ser 
identificado nos discursos dos entrevistados sob formas diversas, sobretudo por meio de expressões de inadequação e incapacidade nas atividades cotidianas, e através dos olhares de crítica e julgamento da sociedade sobre o corpo obeso.

Ao consideramos a pressão e o julgamento que a sociedade exerce sobre os homens, especialmente sobre os padrões estéticos, constatamos que a percepção de si, enquanto corpo obeso, encontra-se alterada devido à imagem corporal negativa. O corpo obeso sentese como se o "seu mundo" não pudesse coexistir com a realidade, levando-o a lançar mão de mecanismos de defesa que o fazem sofrer, tais como a negação e o isolamento evidenciados nesta pesquisa. Esta percepção de si é vivenciada de maneira bastante individual, porquanto a imagem corporal é constituída a partir da percepção subjetiva.

A obesidade apesar de ser encarada como um problema de saúde pública de abrangência mundial, no que tange a Enfermagem, parece estar desamparada e abandonada, visto que o número de estudos que abrangem estas temáticas ainda é bastante escasso.

Destarte, faz-se necessário que a Enfermagem ao coexistir com o corpo obeso na socialidade hospitalar, transcenda as ações de cuidado instrumentais (técnicas). Esta transcendência irá possibilitar um mergulho no mundo privado do corpo obeso, possibilitando percebê-lo na sua multidimensionalidade.

Durante o desenvolvimento desta pesquisa percebi o quanto o corpo obeso é carente de orientações e informações sobre sua saúde. Constatei que a obesidade precisa ser abordada por uma equipe multiprofissional na qual a Enfermeira deve assumir sua responsabilidade enquanto educadora, além de estar atenta às ações de cuidado expressivas, ou seja, as ações de cuidado que estão relacionadas à subjetividade do corpo que carrega as marcas e os significados do vivido em sua trajetória existencial, porquanto ele é produtor e portador de significado, é o veículo do ser no mundo, é a janela através do qual vejo e interajo. Para perceber o outro é preciso a intencionalidade, uma vez que esta propicia a situação de encontro/interação necessária para a concretização do cuidado. A situação de encontro/interação é de fundamental importância no cotidiano da prática de cuidado, porque possibilita estabelecer uma relação de reciprocidade em que há a troca e a complementaridade entre corporeidades.

Compreender a problemática da obesidade, sobretudo a percepção do corpo obeso sobre si, oportunizou a abertura de novos horizontes no que tange a temática e a assistência 
de Enfermagem. Em tempos de humanização, especificamente a humanização do cuidado de Enfermagem, a assistência ao corpo obeso merece especial atenção, pois as estatísticas nos mostram nitidamente que a obesidade faz parte da agenda de saúde pública em nosso país. Neste sentido, devemos refletir se estamos nos preparando efetivamente para atender a demanda pelos serviços de saúde que a população de obesos exige, visto que a obesidade esta associada a fatores de risco, aumentando a incidência das doenças crônicodegenerativas.

Ao término desta caminhada enquanto acadêmica de Enfermagem percebo que esta pesquisa não se encerra. As reflexões aqui desenvolvidas poderão incitar outras acadêmicas e pesquisadoras no aprofundamento da temática, de tal forma que, ao compartilhar o conhecimento gerado, possamos compreender o mundo do corpo que enquanto forma é obeso, possui superficialidade e profundidade, que ao buscar (re)formar sua forma disforme, vivencia uma trajetória marcada pela percepção negativa que gera sentimentos de tristeza, depressão, isolamento, perda da auto estima. Assim, ao conhecermos a percepção que o corpo obeso tem de si, podemos ajudá-lo na superação das dificuldades e dos obstáculos, e desta forma, estaremos cuidando.

\begin{abstract}
This is a phenomenological enlightenment research grew in Maurice Merleau-Ponty's fought, which objective is to comprehend the obese body perception about himself. There were realized 10 recorded interviews from January $20^{\text {th }}$ to February $20^{\text {th }} / 2003$ with obese clients in attendance at the nutritional clinic of a big teaching hospital in the city of Curitiba. The speeches' analysis happened by the three moments the description, the reduction and the phenomenological comprehension, what permitted the identification of a thematic unit which was subjectively classified as "the body image alteration bringing sadness feeling and the isolation". Was evidenced that the self protection mechanisms, body denial and the isolation are frequent behaviors and they are aligned to the low self steam in the obese bodies. These mechanisms are relatively unconscious, wrapping up self deception and reality alteration, maybe constitute bad adapted answers to the stress. The body image alteration added to low self steam in the obese bodies are behaviors which mean dissatisfaction to themselves. Was evidenced that the society, by determining the beauty standards of "skinny - beauty", at the same time that excludes the obese bodies form his environment, provokes disdain feelings and worthiness related to themselves.
\end{abstract}

Key words: Nursing, Body image, Obesity

\title{
REFERÊNCIAS
}

1 APPOLINÁRIO, J. C. Obesidade e psicopatologia. In: HALPERN, A. et al. (Org.). Obesidade. São Paulo: Lemos, 1998. p.217-223. 
2 ASSOCIAÇÃO BRASILEIRA PARA ESTUDOS DA OBESIDADE. Disponível em: http://www. abeso.org.br Acesso em: 16 fev.2003.

3 BALLONE, G.J. Da emoção à lesão. São Paulo: Manole, 2002.

4 BICUDO, M.A.V. Fenomenologia: confrontos e avanços. São Paulo: Cortez, 2000.

5 BRUNNER; L.S. SUDDARTH, D.S. Tratado de enfermagem médico cirúrgica. 8.ed. Rio de Janeiro: Guanabara Koogan, 1999. v.1.

6 CORDÁS, T.A. Participação do psiquiatra e do psicólogo na fase perioperatória: A participação do psiquiatra. In: GARRIDO JUNIOR, A Cirurgia da obesidade. São Paulo: Atheneu, 2002. p.71-74.

7 DAMIANI, D. Obesidade na infância e adolescência: um extraordinário desafio! Arq. Bras. Endocrinol. Metabol., São Paulo, v.44, n.5, p.363-365. out. 2000.

8 DEMO, Pedro. Metodologia científica em Ciências Sociais. 3 ed. São Paulo: Atlas, 1995.

9 FRANQUES, A R.M. Participação do psiquiatra e do psicólogo na fase perioperatória. B - participação do psicólogo. In: GARRIDO JR.A., Cirurgia da obesidade. São Paulo: Atheneu, 2002. p. 74-79.

10 GONÇALVES, M.A.S. Sentir, pensar e agir: corporeidade e educação. 4. ed. São Paulo: Papirus, 2000.

11 KAPLAN, H.I.; SADOCK, B.J.; GEBB, J.A. Compêndio de psiquiatria: ciências do comportamento e psiquiatria clínica. 7. ed: Porto Alegre: Artes Médicas, 1997.

12 LABRONICI, L.M. A corporeidade propiciando o coexistir da racionalidade e sensibilidade nas práticas de cuidar.Curitiba, 1998. 141p. (Dissertação) Rede de PósGraduação em Enfermagem - REPENSUL Extensão Pólo I - Universidade Federal do Paraná, Universidade Federal de Santa Catarina.

13 LABRONICI, L.M. A corporeidade no cenário da clínica ortopédica. Porto Alegre: Suliani, 1999.

14 LABRONICI, L.M. Eros propiciando a compreensão da sexualidade das enfermeiras. Florianópolis, 2002. Tese (Doutorado em Enfermagem) - Universidade Federal de Santa Catarina.

15 MARTINS, J. Um enfoque fenomenológico do currículo: educação como poiésis. São Paulo: Cortez, 1992. 
16 MERLEAU-PONTY, M. Fenomenologia da percepção. São Paulo: Martins Fontes, 1994.

17 MERLEAU-PONTY, M. O visível e o invisível. São Paulo: Perspectiva, 1992.

18 REPETTO, G. Histórico da obesidade. In: HALPERN, A. et al. (Org.). Obesidade. São Paulo: Lemos 1998. p.3-13.

20 SAllet, J. A; MARCHESINI, J. C. D.; SANTOS PAIVA, D. Passos técnicos da remoção do balão intragástrico. In: SALLET, J. A. Balão intragástrico: gastroplastia endoscópica para o tratamento da obesidade. São Paulo: Caminho Editorial, 2001.

21 SCHILDER, P. A imagem do corpo: as energias construtivas da psique. São Paulo: Martins Fontes, 1980.

22 SHAW, S.; D’ANGOUR, A. A Arte de nadar. São Paulo: Manole, 2001.

23 SICHIERI, R. Epidemiologia da obesidade. Rio de Janeiro: Editora da UERJ, 1998.

24 STUART, G.W.; LARAIA, M.T. Enfermagem psiquiátrica. 4.ed. Rio de Janeiro: Reichmann \& Affonso Editores, 2002.

25 TAYLOR, C. M. Fundamentos de enfermagem psiquiátrica. 13. ed. Porto Alegre: Artes Médicas, 1992.

26 TONIAL, S.R. Desnutrição e obesidade: faces contraditórias na miséria e abundância. Recife: Instituto Materno Infantil de Pernambuco, 2001.

27 WADDEN, T.A. STUNKARD, A.J. Psychosocial consequences of obesity and dieting research and clinical findings. In: WADDEN, T.A. STUNKARD, A.J. Obesity: theory and Therapy. 2. ed. New York: Raven Press, 1993.

28 ZOTTIS, C.; SOUZA, R.H.S.; BURIN, D.A P. Gastroplastia: uma alternativa para a qualidade de vida no tratamento da obesidade mórbida. In: CONGRESSO BRASILEIRO DE ENFERMAGEM, 54, 2002, Fortaleza. Anais... Fortaleza: ABEn, 2002. 